\section{An Improved Technique for High Resolution Mitotic Chromosome Studies in Solanum}

\author{
Qin Chen ${ }^{1}$ and Hai Y. Li \\ Agriculture and Agri-Food Canada, Lethbridge Research Centre, P.O. Box \\ 3000, Lethbridge, AB, T1J 4B1 Canada
}

Additional index words. potato, mitosis, cytogenetics, Mexican wild potato species

\begin{abstract}
An improved method is described for the isolation of potato metaphase chromosomes for karyotypic and cytogenetic studies. Root tips from diploid Mexican species, Solanum pinnatisectum $(2 n=2 x=24)$ and tetraploid cultivated $S$. tuberosum $(2 n=4 x$ $=48$ ) were given four different pretreatments. The synthetic pyrethroid, Ambush, was the most stable and effective pretreatment reagent, providing the highest percentage of mitotic chromosomes at metaphase and the best spread of countable chromosomes for cytogenetic studies. Compared with an Ambush pretreatment at concentrations of 100-400 ppm, 1 to 10 ppm Ambush produced more easily distinguished chromosomes, which can be useful for comprehensive observation and karyotype analysis in both $2 x$ and $4 x$ potato species. This improved technique for examining mitotic chromosomes will be helpful in describing karyotypes, characterization of new hybrids, and identifying chromosome structural changes that are important in breeding schemes.
\end{abstract}

In plants, cytogenetic analysis has been widely used in studies of genetics, evolution, phylogeny, origin and taxonomy, as well as determining breeding strategies and the transfer of resistance genes through ploidy manipulation. However, chromosome identification is more of a challenge in many plant species with small chromosomes, such as potato (Solanum tuberosum L.). This is mainly due to difficulty in the preparation of good chromosome spreads, small chromosome size with similar morphology, and the low natural frequency of synchronously dividing cells in root-tip meristems. A high quality, well spread chromosome preparation is critical to enable routine work on potato ploidy manipulation, and physical gene localization by in situ hybridization for future advances in plant cytogenetics (Pijnacker and Ferwerda, 1984; Sybenga, 1992; Visser et al., 1988; Wagenvoort et al., 1994).

Obtaining metaphase chromosomes from root tip cells is a common procedure in plant cytogenetics. Pretreatment of root tips with different reagents can dramatically affect the status of mitosis in root tips and influence the reliability of observations on the shape and size of chromosomes and the number of cells

Received for publication 2 Apr. 2004. Accepted for publication 12 Aug. 2004. The authors thank Dermot Lynch and Debbie Beasley for providing the two cultivated potato lines and for the propagation of the potato materials used in this study. We thank Robert Conner and François Eudes for their critical review of the manuscript and NSERC for providing a visiting fellowship to the junior author. The financial support provided by the Matching Investment Initiative of Agriculture and Agri-Food Canada that was matched to funds from the Potato Growers of Alberta, Midwest Food Products Inc., Keystone Vegetable Producers Association Inc. is gratefully appreciated. This is LRC contribution no. 38703102

${ }^{1}$ To whom reprint requests should be addressed; e-mail chenqi@agr.gc.ca. at metaphase division (Darlington and $\mathrm{La}$ Cour, 1969; Sharma and Sharma, 1965). Many pretreatment reagents, such as ice cold water, 8-hydroxyquinoline, colchicine, and alphacells at metaphase and condense chromosomes during mitosis (Singh, 1993). However, there is no universal protocol that consistently provides adequate mitotic cells for potato chromosome observation. A new tool would be useful for the further characterization and identification of potato chromosomes.

Several insecticides, such as Ambush 25 EC from the pyrethroid group, have an influence on karyokinetic spindle formation (disturbances) during mitosis and meiosis in different plant species, such as Vicia faba L. (Amer and Ali, 1983, 1986; Amer and Mikhael, 1986), Hordeum vulgare L. (Kabir and Alam, 1986), and Allium cepa L. (Klein, 1990). Pretreatment with paradichlorobenzene (PDB) was applied on soybean [Glycine max (L.) Merr.] root tips and affected the mitotic metaphase index at low temperatures (Palmer and Heer, 1973). In this study, different pretreatment methods were evaluated for observation of mitotic chromosomes in potato root tips to develop a more reliable procedure for the resolution of chromosome characteristics and cytogenetic analysis.

\section{Materials and Methods}

Potato materials used in this study included two accessions PI 275233 and PI 275236 from a wild diploid Mexican species Solanum pinnatisectum Dunal ( $p n t, 2 n=2 x=24$ ) and two breeding lines, CQ 123-25 and S 440 from the cultivated tetraploid potato $S$. tuberosum ssp. tuberosum $(t b r, 2 n=4 x=48)$. The plants from these four materials were maintained and propagated by tissue culture in MS medium (Murashige and Skoog, 1962). After 4 to 5 bromonaphthalene can effectively accumulate weeks of subcultures, the plants about 5 to 10 $\mathrm{cm}$ in height were transplanted into small pots $(10 \times 10 \times 12 \mathrm{~cm})$, which contained Cornell soilless mixture of 1 part of sphagnum peatmoss and 2 parts of horticultural grade vermiculite, and grown in a greenhouse under an 18-h light and 6-h dark photoperiod at 18 to $20^{\circ} \mathrm{C}$. About 1 to 2 weeks after transplanting, the 1 to $2 \mathrm{~cm}$ long roots were collected from the plants by inverting the pots, and were dipped into $2 \mathrm{~mL}$ of pretreatment reagents contained in $1 \mathrm{~cm}$ diam test tubes. The root tips were sampled a total of three times at different dates spaced at 1-week intervals. For each sampling date, at least three root tips were collected from each line for every pretreatment. The results obtained from the three samplings on each line were combined to compare the different pretreatment methods for mitotic chromosome observation.

The four pretreatment methods used in this study included the following: T1, ice water for $24 \mathrm{~h}$ at $4{ }^{\circ} \mathrm{C}$; and T2, $10 \mathrm{ppm}$ Ambush for $24 \mathrm{~h}$ at $4{ }^{\circ} \mathrm{C}$ based on the treatment conditions described by Klein (1990). Ambush is a synthetic pyrethroid insecticide, a permethrin (Ambush, Pounce, Ectiban) \{3-phenoxyphenyl methyl $(+,-)$ - cis, trans-3- (2, 2-dichloroethenyl) -2, 2- dimethyl cyclopropanecarbox-ylate) (ICI America, Inc, Wilmington, Del.); and T3, 2 mM 8-hydroxyquinoline for $4 \mathrm{~h}$ at $21^{\circ} \mathrm{C}$ according to the conditions described by Tjio and Levan (1950); and T4, CIMMYT solution-a mixture containing 40 drops $/ 100 \mathrm{~mL}$ of DMSO, $0.025 \%$ 8 -hydroxyquinoline, and $0.05 \%$ colchicine for $4 \mathrm{~h}$ at $21^{\circ} \mathrm{C}$ (Chen et al., 1998).

After pretreatment, the root tips were fixed in a 1:3 solution of glacial acetic acid: ethanol for 1 to $7 \mathrm{~d}$ at $4{ }^{\circ} \mathrm{C}$, followed by chromosome staining with $0.5 \%$ acetocarmine for 10 to 20 $\mathrm{min}$, and then root tip squashing in $45 \%$ acetic acid. Chromosome observation was conducted using an Olympus BX51 microscope with magnification ranging from $100 x$ to $1000 x$. Comparison of the four pretreatment methods for chromosome observation was carried out by counting the total number of cells, the percentage of mitotic chromosomes at metaphase, and the percentage of countable mitotic cells with well spread chromosomes on a slide for each line. A mitotic index was determined using the following methods: 3 to 5 root tips per experiment for each line, and 250 cells per root tip were randomly analyzed. This procedure was repeated twice to determine the mean mitotic index (number of cells at metaphase $\times 100 /$ total number of cells).

Based on the preliminary results, 1, 10, 100,200 , and $400 \mathrm{ppm}$ of Ambush were evaluated to optimize the concentration of Ambush pretreatment.

Duncan's multiple range procedure provided by the General Linear Model (GLM) program of SAS (SAS Institute Inc., Cary, N.C.) was used to compare the percentage of metaphase chromosomes and countable mitotic cells $(P<0.01)$.

\section{Results}

Table 1 summarizes the mitotic indices 
Table 1. Effect of different pretreatment methods on the mitotic index of root tips of genotypes from a wild diploid Mexican species, $S$. pinnatisectum (pnt, $2 n=2 x=24)$ and a cultivated tetraploid species S. tuberosum $(t b r, 2 n=4 x=48)$.

\begin{tabular}{|c|c|c|c|c|c|c|}
\hline \multirow{2}{*}{$\begin{array}{l}\text { Solanum } \\
\text { species }\end{array}$} & \multirow[b]{2}{*}{ Treatment $^{\mathrm{y}}$} & \multicolumn{5}{|c|}{ Mitotic index (number of cells) ${ }^{\mathrm{z}}$} \\
\hline & & Total & Metaphase & Metaphase (\%) & Countable $^{x}$ & Countable $(\%)$ \\
\hline \multirow[t]{4}{*}{$\overline{p n t}$} & T1-ice water & 898 & 30 & $3.3 \mathrm{~b}^{\mathrm{w}}$ & 2 & $6.7 \mathrm{c}$ \\
\hline & $\mathrm{T} 2-$ Ambush & 873 & 70 & $8.0 \mathrm{a}$ & 28 & $40.0 \mathrm{a}$ \\
\hline & T3-8-Hydro & 855 & 20 & $2.3 \mathrm{~b}$ & 4 & $20.0 \mathrm{~b}$ \\
\hline & T4-mixture & 883 & 7 & $0.8 \mathrm{c}$ & 0 & $0.0 \mathrm{c}$ \\
\hline \multirow[t]{4}{*}{$t b r$} & T1-ice water & 860 & 32 & $3.7 \mathrm{~b}$ & 4 & $12.5 \mathrm{c}$ \\
\hline & $\mathrm{T} 2-$ Ambush & 845 & 58 & $6.9 \mathrm{a}$ & 32 & $55.2 \mathrm{a}$ \\
\hline & T3-8-Hydro & 905 & 13 & $1.4 \mathrm{c}$ & 3 & $23.1 \mathrm{~b}$ \\
\hline & T4-mixture & 899 & 13 & $1.4 \mathrm{c}$ & 1 & $7.7 \mathrm{c}$ \\
\hline
\end{tabular}

${ }^{2}$ The results obtained from two wild diploid and two cultivated tetraploid potato lines were combined respectively.

y 1 = pretreatment with ice water for $24 \mathrm{~h}$; T2 $=10 \mathrm{ppm}$ Ambush for $24 \mathrm{~h}$ at $4{ }^{\circ} \mathrm{C}$; T3 $=2$ mM 8 -hydroxyquinoline for $4 \mathrm{~h}$ at $21^{\circ} \mathrm{C}$; T4 = CIMMYT mixture solution for $4 \mathrm{~h}$ at $21^{\circ} \mathrm{C}$.

${ }^{x}$ Number of cells that were well spread and usable for chromosome counting.

${ }^{w}$ Means followed by different letters were significantly different at $P<0.01$.

Table 2. Effect of different concentrations of Ambush on the mitotic index of root tips of one wild diploid species $S$. pinnatisectum (pnt, $2 n=2 x=24$ ) and one cultivated tetraploid $S$. tuberosum $(t b r, 2 n=4 x$ $=48)$.

\begin{tabular}{|c|c|c|c|c|c|c|}
\hline \multirow{2}{*}{$\begin{array}{l}\text { Solanum } \\
\text { species }\end{array}$} & \multirow{2}{*}{$\begin{array}{l}\text { Ambush } \\
\text { (ppm) }\end{array}$} & \multicolumn{5}{|c|}{ Mitotic index (number of cells) } \\
\hline & & Total & Metaphase & Metaphase $(\%)$ & Countable $^{z}$ & Countable $(\%)$ \\
\hline \multirow[t]{5}{*}{ pnt } & 1 & 870 & 78 & $9.0 \mathrm{a}^{\mathrm{y}}$ & 39 & $50.0 \mathrm{a}$ \\
\hline & 10 & 854 & 78 & $9.1 \mathrm{a}$ & 41 & $52.6 \mathrm{a}$ \\
\hline & 100 & 832 & 70 & $8.4 \mathrm{a}$ & 37 & $52.9 \mathrm{a}$ \\
\hline & 200 & 799 & 28 & $3.5 \mathrm{~b}$ & 7 & $25.0 \mathrm{~b}$ \\
\hline & 400 & 760 & 6 & $0.8 \mathrm{c}$ & 1 & $16.7 \mathrm{c}$ \\
\hline \multirow[t]{5}{*}{$t b r$} & 1 & 736 & 60 & $8.2 \mathrm{a}$ & 36 & $60.0 \mathrm{a}$ \\
\hline & 10 & 790 & 67 & $8.5 \mathrm{a}$ & 38 & $56.7 \mathrm{a}$ \\
\hline & 100 & 630 & 53 & $8.4 \mathrm{a}$ & 30 & $56.6 \mathrm{a}$ \\
\hline & 200 & 805 & 25 & $3.1 \mathrm{~b}$ & 5 & $20.0 \mathrm{~b}$ \\
\hline & 400 & 559 & 6 & $1.1 \mathrm{~b}$ & 1 & $16.7 \mathrm{c}$ \\
\hline
\end{tabular}

${ }^{\mathrm{z}}$ Number of cells that were well spread and usable for chromosome counting.

${ }^{\mathrm{y}}$ Means followed by different letters are significantly different at $P<0.01$.

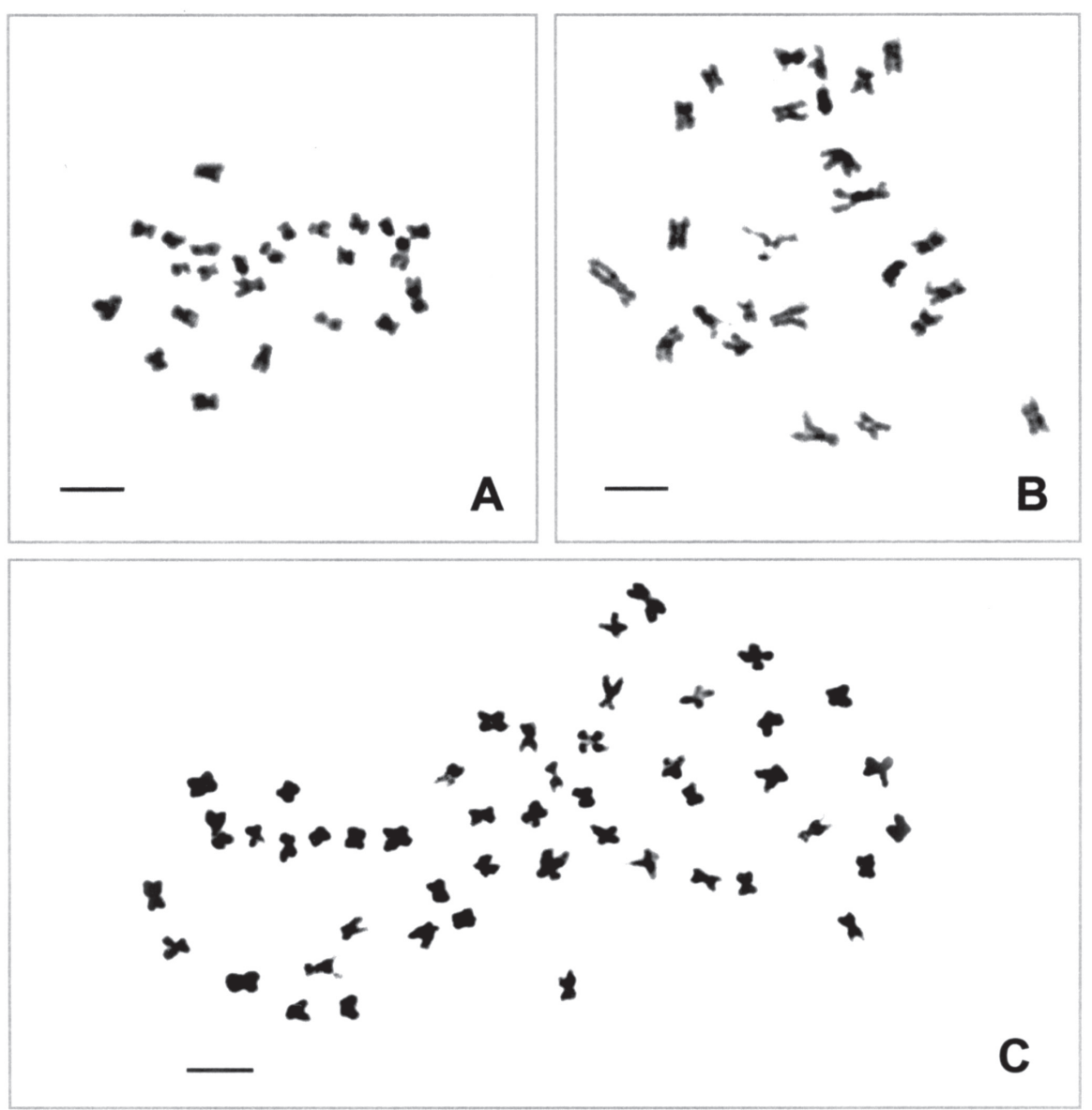

obtained from preliminary tests of the four pretreatment methods on potato root tips. The data for the two clones from Mexican diploid wild species and two lines from tetraploid cultivated potato were combined, respectively, since there was no major difference in the mitotic indices between them. Results showed that pretreatment with $10 \mathrm{ppm}$ Ambush (T2) gave the highest percentage of metaphase cells (6.9\% to $8.0 \%)$ and the best-spread countable chromosomes ( $40.0 \%$ to $55.2 \%$ ), which were significantly higher than observed in the other three treatments for the potato species tested. A high frequency (up to 50\%) of metaphase cells in one view could be used for chromosome counting. Pretreatment with ice water(T1) produced a higher percentage of metaphase cells than treatments with 8-hydroxyquinoline (T3) and CIMMYT solution (T4) in the tetraploid cultivated potato lines, but the percentage of countable metaphase cells was lower in diploid than tetraploid lines in the 8-hydroxyquinoline treatment.

Based on the preliminary results, another experiment with the Ambush pretreatment at different concentrations $(1,10,100,200$, and $400 \mathrm{ppm}$ ) was carried out to evaluate the effect of the concentration of Ambush on chromosome accumulation (Table 2). Concentrations of 1 to $100 \mathrm{ppm}$ gave similarly high percentages of metaphase cells and countable cells, which were significantly superior to those of the 200 and $400 \mathrm{ppm}$ treatments. Pretreatments with lower concentrations ( 1 and $10 \mathrm{ppm}$ ) of Ambush also provided the most distinguishable shapes and larger chromosomes in both of the $p n t$ and $t b r$ species (Fig. 1). Concentrations of more than $100 \mathrm{ppm}$ resulted in overcondensed metaphase chromosomes, which might be desirable for chromosome counting, but were not suitable for banding or in situ hybridization studies where spatial resolution of the chromosomes is needed. It was noted that pretreatment with Ambush for $20 \mathrm{~h}$ at $4{ }^{\circ} \mathrm{C}$ resulted in longer chromosomes (Fig. 1B) than treatment for $24 \mathrm{~h}$ (Fig. 1A).

\section{Discussion}

The results presented showed that Ambush is an effective pretreatment reagent, producing better results for chromosome counts and cytogenetic analysis than the other three treatments. Using a concentration (1 to $10 \mathrm{ppm}$ ) of Ambush at a low temperature (about $4{ }^{\circ} \mathrm{C}$ ) can significantly increase the mitotic index and produced the best separation of single chromosomes and well-spread metaphases (Table 1, Fig. 1). Using this technique, we could count 20 to 40 dividing cells for each slide preparation. This Ambush pretreatment method not only worked well on diploid species, but also on polyploid species, such as

Fig. 1. Mitotic metaphase chromosomes of the Mexican diploid species $S$. pinnatisectum PI 275233 (A), PI 275236 (B) and tetraploid potato plant (C). The metaphase cells were obtained from 1 to $10 \mathrm{ppm}$ Ambush pretreatment. The photographs were taken at a magnification of $1000 \times$. Bar $=10 \mu \mathrm{m}$. 
tetraploid potato with many chromosomes (Fig. 1C). Compared to traditional chromosome counting procedures, the present technique is simple, rapid and convenient for the detection and characterization of chromosomes in potato. Ambush pretreatment may be superior due to its disruption of karyokinetic spindles causing C-mitotic changes in plant mitotic cells (Klein, 1990). The inhibition of mitosis by Ambush, like many other alternative reagents including spindle poison herbicides (Dolezel et al., 1998), caused irregularities of the C-mitosis type, such as multinucleate cells and those containing restitution nuclei.

The present technique provides several advantages that make it suitable for cytogenetic study. The major advantages of Ambush in comparison with the other pretreatments, such as 8-hydroxyquinoline and cold water are as follows.

1) It provides higher quality of metaphase spreads. More than $50 \%$ of metaphases prepared using this method are well spread and usable for chromosome counting, whereas other pretreatments do not always show the desirable results.

2) The size and shape of chromosomes can be adjusted by using different concentrations and times of treatments. Usually, pretreatment with 1 to $10 \mathrm{ppm}$ Ambush for a short time (about $20 \mathrm{~h}$ instead of $24 \mathrm{~h}$ ) provides longer and distinguishable shaped chromosomes (Fig. 1). The longer chromosomes obtained using the present method (3.20 to $6.87 \mu \mathrm{m}$ in pnt, data not shown), compared with those reported for small potato chromosomes ( 1 to $3.0 \mu \mathrm{m}$ ), would permit an accurate evaluation of chromosome morphology (Dong et al., 2000).

3) It is applicable to both diploid and polyploid species even though chromosome counting is always more difficult in polyploid species.

4) It can be applied to other plant species, especially those with many small chromosomes.

\section{Literature Cited}

Amer, S.M. and E.M. Ali. 1983. Cytological effects of pesticides VI. Effect of the insecticide "Rogor" on the mitosis of Vicia faba and Gossypium barbadense. Cytologia 39:507-514.

Amer, S.M. and E.M. Ali. 1986. Cytological effects of pesticides XVII. Effect of the insecticide dichlorvos on root-mitosis of Vicia faba. Cytologia 51:21-25.

Amer, S.M. and E. Mikhael. 1986. Cytological effects of pesticides XVI. Effect of the insecticide Rotenone on root-mitosis of Viciafaba. Cytologia 51:171-176.

Chen, Q., F. Ahmad, J. Collin, A. Comeau, G. Fedak, and C.A. St-Pierre. 1998. Genomic constitution of a partial amphiploid OK7211542 used as a source of immunity to barley yellow dwarf virus for bread wheat. Plant Breeding 117:1-6.

Darlington, C.D. and L.F. La Cour. 1969. The handling of chromosomes. 5th ed. George Allen \& Unwin Ltd., London.

Dolezel, J., M. Dolezelova, N. Roux, and I. Van den Houwe. 1998. A novel method to prepare slides for high resolution chromosome studies in Musa spp. Infomusa 7:3-4.

Dong, F., J. Song, S.K. Naess, J.P. Helgeson, C. Gebhardt, and J. Jiang. 2000. Development and applications of a set of chromosome-specific cytogenetic DNA markers in potato. Theor. Appl. Genet. 101:1001-1007.

Kabir, G. and S. Alam. 1986. Cytological effects of insecticides (Carbieron-100 EC and Vapona50) on barley (Hordeum vulgare L.). Cytologia 51:885-892.

Klein, M. 1990. C-mitotic action of the insecticide Ambush 25 EC in Allium cepa L. Genet. Polonica 31:107-113.

Murashige, T. and F. Skoog. 1962. A revised medium for rapid growth and bioassays with tobacco tissue culture. Physiol. Plant 15:473-497.

Palmer, R.G. and H. Heer. 1973. A root tip squash technique for soybean chromosomes. Crop Sci. 13:389-391.

Pijnacker, L.P. and M.A. Ferwerda. 1984. Giemsa C-banding of potato chromosomes. Can. J. Genet. Cytol. 26:415-419.

Sharma, A.K. and A. Sharma. 1965. Chromosome Techniques-Theory and Practice. Butterworths, London.

Singh, R.J. 1993. Plant cytogenetics. CRC Press, Inc., Boca Raton, Fla.

Sybenga, J. 1992. Cytogenetics in plant breeding. Springer-Verlag, Berlin.

Tjio, J.H. and A. Levan. 1950. The use of oxyquinoline in chromosome analysis. Ann. Estacion Expt. Aula Dei. 2:21-46.

Visser, R.G., R. Hoekstra, L. Vander, L.P. Pijnacker, B. Witholt, and W.J. Feenstra. 1988. In situ hybridization to somatic metaphase chromosomes of potato. Theor. Appl. Genet. 76:420-424.

Wagenvoort, M., G.J.A. Rouwendal, G. KuiperGroenwold, and H.P.J. De vries van Hulten. 1994 Chromosome identification in potato trisomics $(2 n=2 x+1=25)$ by conventional staining, giemsa $\mathrm{C}$-banding and non-radioactive in situ hybridization. Cytologia 59:405-417. 